\title{
Glycogen Storage Disease Type IV: Inherited Deficiency of Branching Enzyme Activity in Cats
}

\author{
JOHN C. FYFE, URS GIGER, THOMAS J. VAN WINKLE, MARK E. HASKINS, \\ SHELDON A. STEINBERG, PING WANG, AND DONALD F. PATTERSON \\ Sections of Medical Genetics [J.C.F., U.G., M.E.H., P.W., D.F.P.] and Neurology [S.A.S.], Department of \\ Clinical Studies and Department of Pathobiology [T.J.V.W., M.E.H.], School of Veterinary Medicine, University \\ of Pennsylvania, Philadelphia, Pennsylvania 19104-6010
}

\begin{abstract}
Glycogen storage disease type IV due to branching enzyme deficiency was found in an inbred family of Norwegian forest cats, an uncommon breed of domestic cats. Skeletal muscle, heart, and CNS degeneration were clinically apparent and histologically evident in affected cats older than 5 mo of age, but cirrhosis and hepatic failure, hallmarks of the human disorder, were absent. Beginning at or before birth, affected cats accumulated an abnormal glycogen in many tissues that was determined by histochemical, enzymatic, and spectral analysis to be a poorly branched $\alpha-1,4-\mathrm{D}$-glucan. Branching enzyme activity was less than 0.1 of normal in liver and muscle of affected cats and partially deficient (0.17-0.75 of normal) in muscle and leukocytes of the parents of affected cats. These data and pedigree analysis indicate that branching enzyme deficiency is a simple autosomal recessive trait in this family. This is the first reported animal model of human glycogen storage disease type IV. A breeding colony derived from a relative of the affected cats has been established. (Pediatr Res 32: 719-725, 1992)
\end{abstract}

Glycogen storage disease type IV (Andersen disease, amylopectinosis, McKusick catalogue no. 232500) is a rare, inherited disorder of glycogen metabolism in humans caused by deficiency of $\alpha-1,4$ glucan: $\alpha-1,4$ glucan 6-glycosyl transferase (EC 2.4.1.18), the glycogen branching enzyme (1-5). An abnormal glycogen that superficially resembles amylopectin, containing longer chain lengths and fewer branch points than normal glycogen $(2,6,7)$, is found in skeletal, smooth, and cardiac muscle, central and peripheral nervous systems, liver, and cells of the reticuloendothelial system $(1,2,8,9)$. Fewer than 50 patients with biochemically confirmed glycogen storage disease type IV have been reported. Most affected children fail to thrive before $1 \mathrm{y}$ of age and die from cirrhosis and the sequelae of hepatic failure between 1 and 4 y of age. Some children exhibit signs of cardiac failure or neuromuscular involvement, with or without signs of hepatic disease $(8,10,11)$, and a few patients with later onset of signs and longer survival have been reported $(10,12,13)$. Orthotopic liver transplantation has been life-saving in a few patients (14). Biochemical evidence and family pedigrees indicate that type IV glycogen storage disease is inherited as an autosomal recessive trait; heterozygote detection and successful prenatal diagnosis have been reported $(12,15,16,17)$.

\footnotetext{
Received April 19, 1992; accepted July 29, 1992.
}

Correspondence and reprint requests: John C. Fyfe, D.V.M., Section of Medical Genetics, Veterinary Hospital of the University of Pennsylvania, 3850 Spruce Street, Philadelphia, PA 19104-6010.

Supported by the NIH Referral Center-Animal Models of Human Genetic Disease (RR02512) and the Mrs. Cheever Porter Foundation. J.C.F. was partially supported by the Kleberg Fellowship Program in Veterinary Medical Genetics.
This report describes the clinical, pathologic, biochemical, and genetic characteristics of glycogen storage disease type IV in a family of purebred domestic cats.

\section{MATERIALS AND METHODS}

Animals. Affected cats and their family members were clientowned animals. Unrelated control cats were chosen from colonies maintained by the University of Pennsylvania Unit of Laboratory Animal Resources. All animal-use protocols were approved by the Institutional Animal Care and Use Committee of the University and conformed to National Institutes of Health guidelines.

Histopathology and electron microscopy. Tissues for light microscopy were fixed in $1.25 \mathrm{M}$ neutral buffered formaldehyde ( $10 \%$ formalin), paraffin- or plastic- (glycol methacrylate) embedded, and sectioned. Routine stains included hematoxylineosin, periodic acid-Schiff, toluidine blue, luxol-fast blue Holme's silver, alcian blue, cresyl-fast violet, and oil red $O$. Tissue sections for iodine staining were deparaffinized, rehydrated, placed in Lugol's iodine solution for $2 \mathrm{~min}$, and mounted in glycerol. Tissues for electron microscopy were fixed by overnight immersion at $4^{\circ} \mathrm{C}$ in cacodylate-buffered $0.5 \mathrm{M}(5 \%)$ glutaraldehyde, postfixed in $80 \mathrm{mM}(2 \%)$ osmium tetroxide, en bloc stained with uranyl acetate, and embedded in Spurr's low-viscosity medium. Sections were cut on a Sorval MTZ-B ultramicrotome and stained sequentially with citrate-buffered lead nitrate and uranyl acetate. Sections were examined on a Zeiss EM9S-2 transmission electron microscope.

Enzyme assays. All reference polysaccharides, enzymes, enzyme substrates, and other biochemicals were purchased from Sigma Chemical Co., St. Louis, MO. Leukocytes were separated from fresh heparinized blood by 0.03 dextran centrifugation as described previously (18). Leukocytes from aliquots of some blood samples were enriched to $0.8-0.9$ lymphocytes by gradient centrifugation in Ficoll-Hypaque (19). After separation, leukocytes were washed repeatedly with $150 \mathrm{mM} \mathrm{NaCl}$. Muscle and liver samples were collected postmortem or as biopsies, and all tissues for enzyme assay and glycogen analysis were stored at $-70^{\circ} \mathrm{C}$. Tissue from healthy, age-matched, unrelated control cats was collected and preserved similarly. Branching enzyme activity was measured in leukocytes and tissues by the phosphate-release method of Brown and Brown (3) using boiled aliquots of sample homogenates as negative controls. Protein was measured by the method of Lowry et al. (20). Acid $\alpha$-glucosidase activity was measured at $\mathrm{pH} 4.0$ with $p$-nitrophenyl- $\alpha$-D-glucoside as substrate (21).

Glycogen isolation and characterization. Glycogen was isolated from tissues of affected cats and of normal, unrelated control cats by hot $\mathrm{KOH}$ digestion and repeated ethanol precipitation as described by Somogyi (22), and tissue glycogen concentrations were determined gravimetrically. Iodine absorption spectra of 
the isolated and reference glucans were determined as described (23). Glycogen was also quantitated enzymatically by measurement of glucose released from tissue homogenates after incubation with amyloglucosidase ( $\alpha$-1,4-D-glucan glucohydrolase from Aspergillus niger; EC 3.2.1.3) or amyloglucosidase and $\alpha$-amylase $(\alpha-1,4-\mathrm{D}$-glucan glucanohydrolase from Bacillus sp; EC 3.2.1.1) exo- and endoglucosidases (24).

Statistical analysis. Differences in group means between affected cats, parents, and unrelated normal controls were assessed by the unpaired $t$ test.

\section{RESULTS}

Clinical features. Two related, purebred Norwegian forest cats, a 9-mo-old male (Fig. 1; cat no. 60) and a 12-mo-old female (cat no. 53), were evaluated for a progressive neuromuscular disorder. In both cats, initial signs had developed in the 5 th mo of age and consisted of persistently elevated body temperature (39.5$40.5^{\circ} \mathrm{C}$ ), generalized muscle tremors, intermittent listlessness, and a gait abnormality described as "bunny hopping." Serum tests for exposure to feline leukemia virus, feline infectious peritonitis virus, and Toxoplasma gondii were negative. Muscle weakness and generalized skeletal muscle atrophy had progressed rapidly and resulted in tetraplegia by 7 mo of age. Body temperatures had returned to normal by 8 mo of age.

At the time of presentation, although both cats were alert and responsive to environmental stimuli, neither could move about or stand without assistance, and cat no. 60 could not maintain sternal recumbency. Each cat had spontaneous muscle fasciculations and severe, generalized muscle atrophy. The femorotibial and tibiotarsal joints of cat no. 53 were locked in extension and could not be flexed by the examiner. The carpi and joints of the digits of both cats were flexed but were movable. Neither cat could chew dry cat food, and each exhibited difficulty swallowing solid food. Clinical evaluation of the cranial nerves, except those involved in swallowing, revealed no abnormality. Some voluntary movement of the forelimbs was preserved, but myotatic reflexes were reduced in all limbs. Awareness of a toe pinch was evident from all limbs, but limb withdrawal was absent. Serum creatine phosphokinase ( 85 and $40 \mu \mathrm{kat} / \mathrm{L}$; normal range $1.1-$
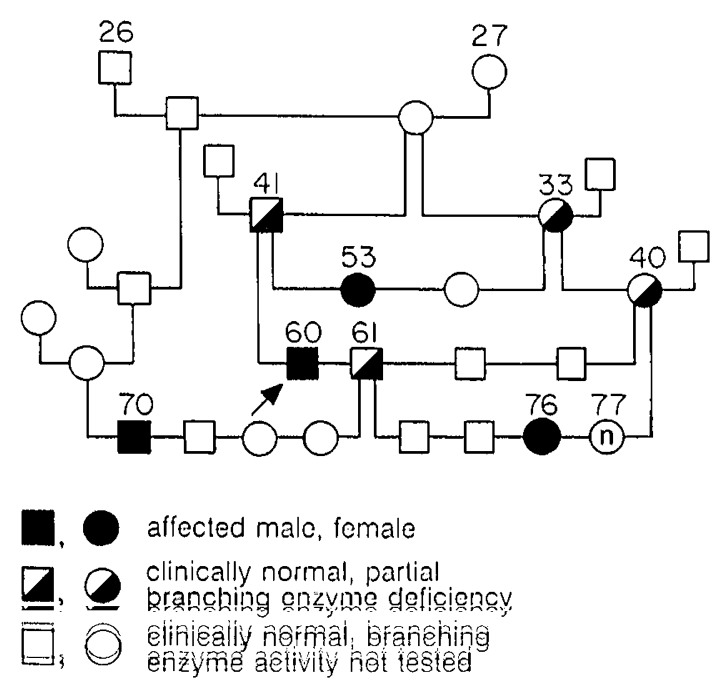

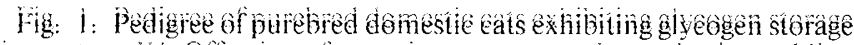
disease type iv: Ofrsping of a mâting are artanged on a horizontal line

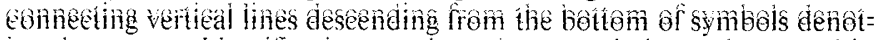
ing the barents: deitifieation numbers above symbols are those used in

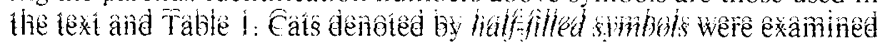
and their cantier status eonfintiod by branehing enzyme assay of biopsy

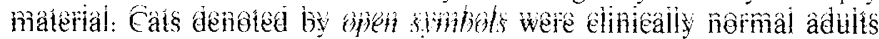

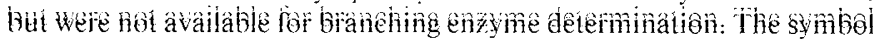

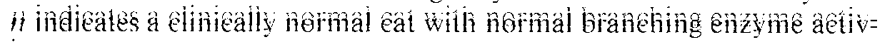
ity:
$6.7 \mu \mathrm{kat} / \mathrm{L})$ and alanine aminotransferase (1.91 and $1.88 \mu \mathrm{kat} /$ $\mathrm{L}$; normal range $0.22-0.95 \mu \mathrm{kat} / \mathrm{L}$ ) activities were each elevated in cats no. 60 and 53, respectively, but other routine serum biochemical tests and results of complete blood cell counts were normal.

Electromyographic examination under general anesthesia of cat no. 60 disclosed spontaneous fibrillation potentials in all muscle groups except the masseter muscles and bizarre highfrequency discharges in the quadriceps and epaxial muscles of the neck. Radial nerve (sensory) and sciatic nerve (motor) conduction velocities and action potentials were normal. Radiographic survey findings included osteopenia of vertebrae and bones of the extremities, attributed to disuse, in both cats and malarticulation of the carpal and tarsal bones of cat no. 53 .

A grade I-II/V systolic murmur was ausculted in cat no. 53, although none had been noted upon examination elsewhere 6 mo earlier. Radiographically, there was mild generalized cardiomegaly. Electrocardiographic examination of this cat revealed a sinus rhythm with occasional ventricular premature contractions, and a left deviation of the mean electrical axis. Concentric left ventricular hypertrophy and mild left atrial dilation were confirmed by two-dimensional and M-mode echocardiography. There was decreased relaxation of the left ventricular wall during diastole, and focal hyperechoic areas were noted in the left ventricular subendocardium. Doppler measurement of intracardiac blood flow revealed mitral valve regurgitation. There was no electro- or echocardiographic evidence of cardiac disease in cat no. 60 .

Cat no. 53 survived with feeding assistance and nursing care at home until 13.5 mo of age, at which time she died with reported signs suggestive of rapid cardiac decompensation. The carcass was cooled and maintained on ice for $42 \mathrm{~h}$ during transport for postmortem examination and freezing of tissues for biochemical analysis. Cat no. 60 was humanely killed at $9 \mathrm{mo}$ of age by i.v. injection of barbiturates, and tissues were collected immediately for histopathologic examination and biochemical analyses.

Pathology. On postmortem examination, cats no. 53 and 60 had severe generalized skeletal muscle atrophy. The cranial thigh muscles of cat no. 53 were virtually replaced by a fibrous band, and the femorotibial and tibiotarsal joints could not be flexed until the patellar tendon was transected. In this cat, the left ventricular myocardium was thickened and the left atrium was dilated.

By light microscopy, there were cytoplasmic inclusions in many organs from both cats that stained pale blue with hematoxylin and eosin, red-purple with periodic acid-Schiff both before and after digestion with diastase, blue with toluidine blue, gray with luxol-fast blue-Holmes silver, and blue to purple with Lugol's iodine. Exposure of the deparaffinized, hydrated sections to hexane before or after iodine staining eliminated the blue reaction of the inclusions in affected cat tissues. The stored material did not stain with alcian blue, cresyl-fast violet, or oil red $O$. Distribution of the material ranged from clusters of granular material displacing the nucleus in some cells to one or more irregular, oval, or round discrete globules in other cells. In many organs where the abnormal material was seen, other pathologic changes were not evident. In particular, the liver was normal exeept for the presence of small sranules of stored máterial in hepatoeytês and lares aecumulations in Kußfer eêlis: Though nót evident in all esll tzos when stained with hematexylin and êsin, the aknormal material was detected, stâning bilue tô purple with iedine, in skeletal muscle of the axtal

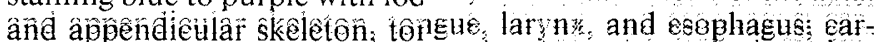

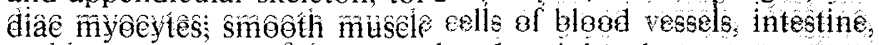
ând lung; neurons of the eentral and peripheral nervous system: âstroeytes; hêpatoeytês; ehona maerephàges of thê spleen, lymph nodes, and liver: glandular epithelial eeils of the stomâch: adrenal medullary eells; lens

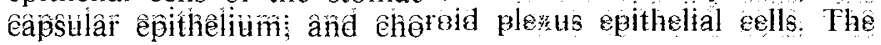


largest accumulations of stored material were in skeletal and cardiac myocytes, neurons of the CNS, and macrophages.

In the nervous system and striated muscle, both skeletal and cardiac, the presence of inclusions was accompanied by extensive degeneration. All skeletal muscles examined had extensive severe multifocal myofiber atrophy, scattered degenerating myocytes with fragmented granular cytoplasm, infiltrating macrophages, and clusters of regenerating myocytes (Fig. 2). The abnormal material was present primarily in the center of morphologically normal myocytes. In the subendothelial myocardium and papillary muscles of the left ventricle, there were fragmented myofibers in both cats and areas of fibrosis and myocyte nuclear hypertrophy in cat no. 53 .

Stored material was present in the perikarya of neurons throughout the central and peripheral nervous systems including the dorsal and ventral horns (Fig. 3) and dorsal root ganglia of the spinal cord, sensory and motor nuclei throughout the brainstem, Purkinje cells in the cerebellum, ganglion cells in the retina, autonomic ganglia, and myenteric plexi of the intestinal tract. There were multiple perivascular cuffs of lymphocytes in both gray- and white-matter areas of the brain and spinal cord. In brainstem nuclear areas with extensive storage, there was a loss
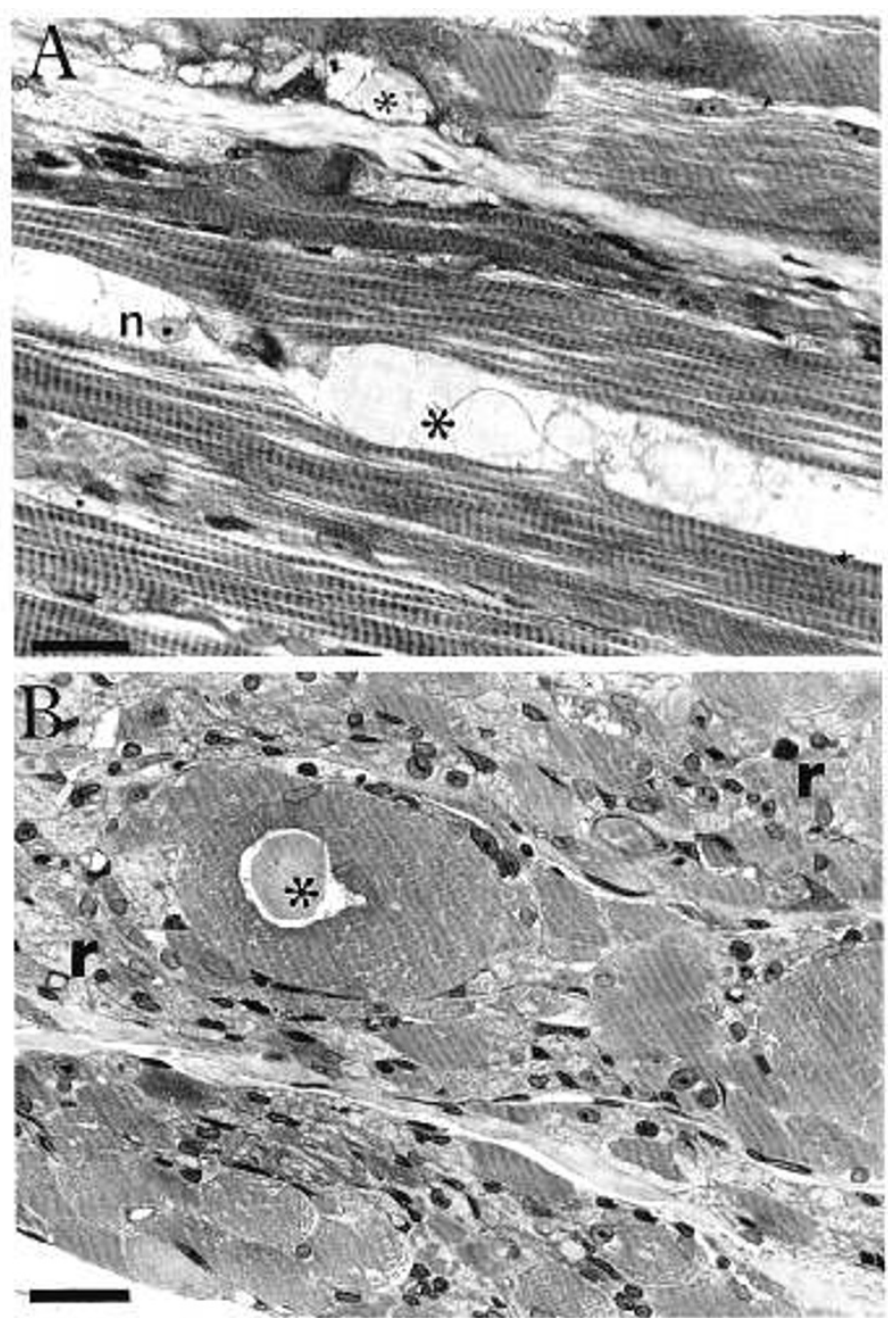

Fig. 2. Light micrograph of thigh muscles from cat no. 60 affected with glycogen storage disease type IV. Fixed tissues were plastic embedded, and $1.5-\mu \mathrm{m}$-thick sections were stained with toluidine blue. Panel A shows a longitudinal section of semitendinosus muscle, and pancl $B$ shows a cross-section of vastus lateralis muscle. The scale bar in each panel indicates $25 \mu \mathrm{m}$. Inclusions of abnormal glycogen $\left(^{*}\right)$ are present in the center of morphologically normal myocytes and among clusters of regenerating myocytes $(r)$. Occasional central nuclei $(n)$ are present.

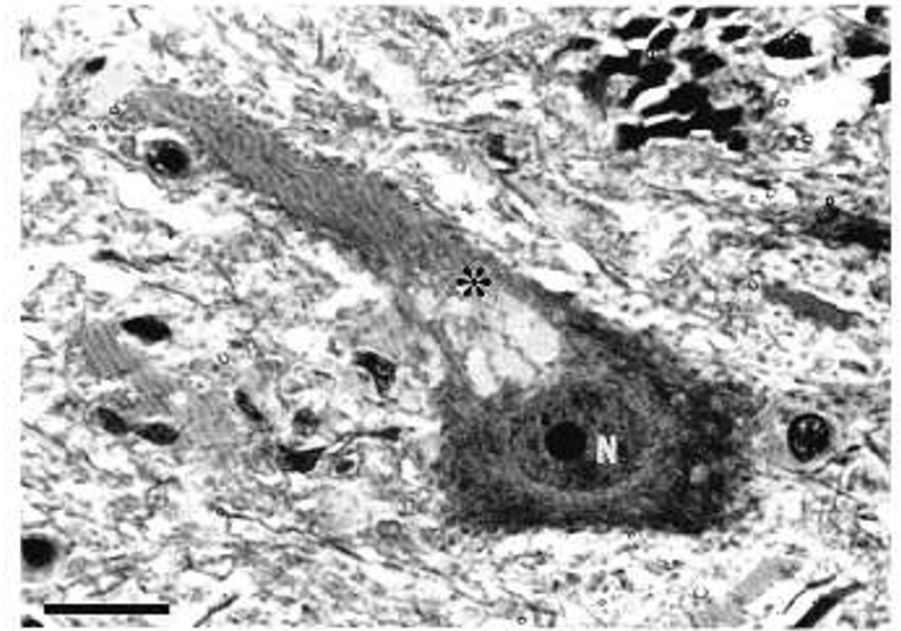

Fig. 3. Light micrograph of ventral horn gray matter of spinal cord segment $\mathrm{C}_{7}$ from cat no. 60 affected with glycogen storage disease type IV. The section was processed as for Figure 2 . The scale bar indicates 20 $\mu \mathrm{m}$. Inclusions of abnormal glycogen $\left(^{*}\right)$ are present in the cytoplasm of a neuron near the nucleus $(N)$ containing a dark-staining nucleolus.

of neuronal cell bodies and an increased number of astrocytes. There was extensive axonal loss and demyelination in the dorsolateral, lateral, and ventral funiculi of the spinal cord and cerebellar peduncles. Myelin sheaths were dilated and frequently contained debris and myelomacrophages. There was decreased affinity for myelin stains in these tracts and an increased number of astrocytes. In peripheral nerves, there was extensive loss of affinity for myelin stains accompanied by loss of axons, swollen axons, and dilated myelin sheaths with debris and myelomacrophages, changes that were most severe distally.

Electron microscopic examination of skeletal myocytes of the vastus lateralis and cervical spinal cord neurons demonstrated irregular cytoplasmic inclusions of finely granular material without a limiting membrane (Fig. 4). In each cell, there were a few to many inclusions, which varied from 0.3 to $5 \mu \mathrm{m}$ in the largest dimension. In some cells, the cytoplasm was crowded with inclusions that appeared to coalesce. Components of other cell structures were entrapped in the larger inclusions. Accumulations of normal-appearing glycogen granules were not present.

A third, related Norwegian forest cat (cat no. 70) died suddenly at home at 5 mo of age with no preceding signs of disease. Postmortem examination was performed by a referring veterinarian, and tissues were submitted for histopathologic examination. Gross and histopathologic evidence suggested that the cat died as the result of a septic pyothorax, which developed subsequent to a small penetrating injury of the thoracic wall. Inclusions with the same distribution and histochemical staining reactions as the abnormal storage material seen in cats no. 53 and 60 were seen in skeletal and smooth myocytes, bronchial chondrocytes, hepatocytes, and Kupffer cells of cat no. 70. There were mild lymphoplasmacytic infiltrates in portal areas of the liver. Skeletal muscle degeneration was not evident, but only a portion of intercostal muscle was submitted. Nervous system tissue and heart were not available for histologic examination.

A fourth, related kitten (cat no. 76) died at home 6 h postnatally and was preserved frozen. Gross and histopathologic examination of the neonate revealed no anatomical abnormalities or apparent cause of death. There were no degenerative changes in liver, heart, sciatic nerve, or skeletal muscle seen histologically, but small granules of periodic acid-Schiff-positive, iodine-positive (blue) material were present in hepatocytes, Kupffer cells, smooth muscle cells of blood vessels, a few skeletal myocytes, and in almost all cardiac myocytes. In cardiac muscle, there appeared to be a gradient of iodine-positive granule size, large accumulations being present in the subendocardium and in 


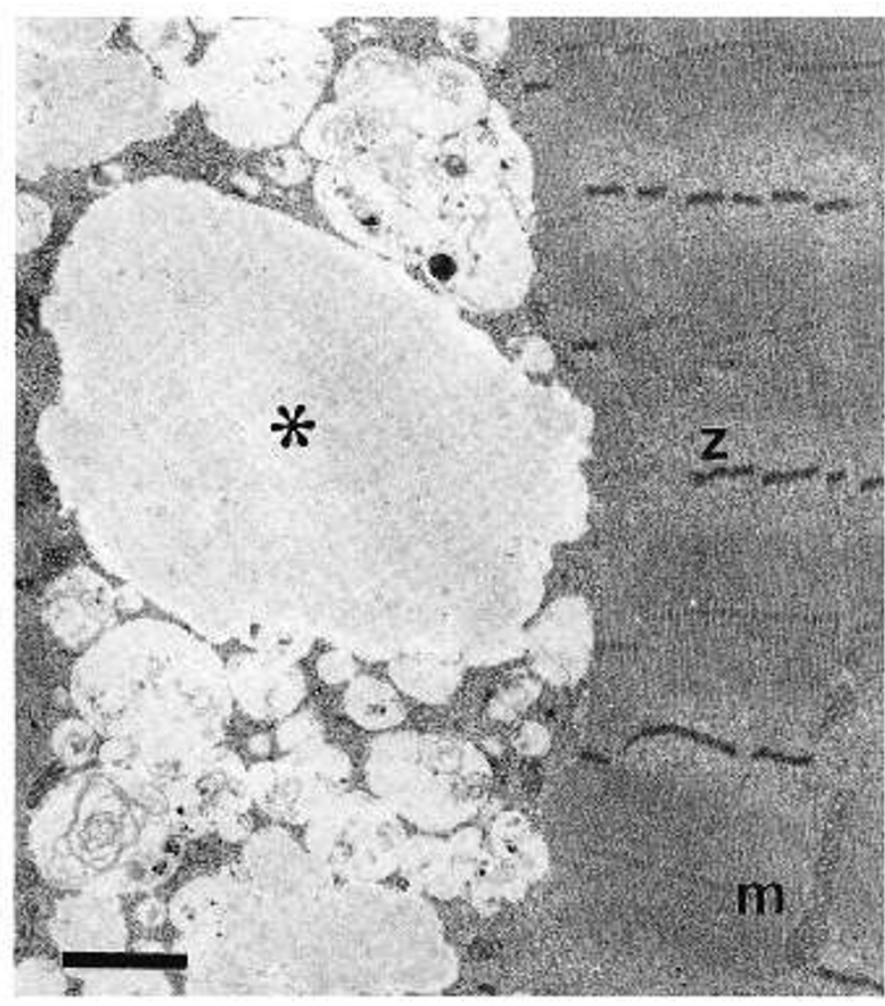

Fig. 4. Electron micrograph of a vastus lateralis myocyte from cat no. 60 affected with glycogen storage disease type IV. Many inclusions of abnormal glycogen $(*)$ are present adjacent to morphologically normal sarcomeres containing $Z$-bands $(z)$ and mitochondria $(m)$. The inclusions vary in size, have no limiting membrane, and often incorporate remnants of cellular structures. The scale bar indicates $1 \mu \mathrm{m}$.

papillary muscles and smaller granules near the epicardial surface. The CNS was not examined.

The histochemical staining reactions, tissue distribution, and subcellular localization of the storage material in the affected cats suggested the tentative diagnosis of glycogen storage disease type IV. The following studies were initiated to test that hypothesis.

Enzyme assays. Branching enzyme activity was measured in homogenates of muscle, liver, and leukocytes of normal, unrelated cats; in muscle and liver of affected cats; and in muscle and leukocytes of the parents and a sibling of affected cats (Fig. 1, Table 1). Branching enzyme activity of affected cats was $0.03-$ 0.10 of normal in liver and muscle. Four of five parents of affected cats were available for study. One of these (cat no. 61) was also a littermate of cat no. 60 , the propositus. The mean branching enzyme activity of the parents of affected cats was 0.32 (range, $0.17-0.71$ ) of normal in muscle and 0.48 (range, $0.34-0.74$ ) of normal in leukocytes. Cat no 77 , a littermate of affected cat no. 76, had normal branching enzyme activity in muscle and leukocytes. In mixing experiments, the specific branching enzyme activity of a normal cat liver homogenate (56 $\mu \mathrm{kat} / \mathrm{g}$ protein) was not changed by the presence of 3 -fold excess affected cat liver homogenate ( $54 \mu \mathrm{kat} / \mathrm{g}$ protein), indicating that the affected cat liver tissue did not contain an inhibitor of branching enzyme activity. Branching enzyme activities of normal neonate tissues were $0.25-0.45$ of those of adult normal cats, indicating the importance of age-similar controls. There was no significant difference in acid $\alpha$-glucosidase activity between affected cats and their parents or unrelated normal cats, and normal neonate and adult cat acid $\alpha$-glucosidase activities were nearly identical (Table 1). The branching enzyme activity of normal cat tissues that were refrigerated for $42 \mathrm{~h}$ before freezing was not reduced compared to fresh frozen tissues, and branching enzymes activity did not vary significantly between total leuko- cytes and leukocyte samples enriched for lymphocytes (data not shown).

Glycogen characterization. The glycogen concentration determined gravimetrically in muscle of two affected cats was about twice that in muscle from two normal cats ( 20 and 28 versus 8 and $14 \mathrm{mg} / \mathrm{g}$ tissue, wet weight, respectively). Though the protein concentration of affected and normal cat muscle samples were similar ( 9.1 and $9.2 \mathrm{mg} / \mathrm{g}$ tissue wet weight, respectively), the atrophic condition of the affected cat muscle may have artifactually increased the glycogen concentration as measured on a whole tissue basis. In an affected cat liver, a tissue without apparent histopathology, the concentration was about one half that measured in the livers of two fed, normal cats (32 versus 50 and $63 \mathrm{mg} / \mathrm{g}$ tissue wet weight, respectively). In a 24-h fasted, normal cat, the hepatic glycogen concentration was $20 \mathrm{mg} / \mathrm{g}$ tissue wet weight. Because the relative nutritional status of the affected cats was not known, it was not clear that the observed differences in hepatic glycogen concentrations between normal and affected adult cats were pathophysiologically meaningful.

In normal cat liver and muscle, the results of enzymatic quantitation of glycogen in tissue homogenates were similar to gravimetric glycogen determinations (above). However, in liver and muscle from affected cats, tissue glycogen determinations by amyloglucosidase hydrolysis were $0.00-0.05$ of those obtained gravimetrically. When the study was repeated in liver homogenates using a mixture of amyloglucosidase, an exoglucosidase, and $\alpha$-amylase, an endoglucosidase, the glycogen concentrations in fed, normal and affected cat samples were 39 and $42 \mathrm{mg} / \mathrm{g}$ tissue wet weight, respectively, results similar to those determined gravimetrically. The resistance of the affected cat glucan to amyloglucosidase hydrolysis suggested a structure poor in enzymatic end groups.

Iodine spectra of the glucans isolated by hot $\mathrm{KOH}$ digestion of normal and affected cat liver and muscle were compared with iodine spectra of rabbit liver glycogen, corn amylopectin, and potato starch as representatives of poly $(\alpha-1,4-D)$ glucosides with high, intermediate, and little branching, respectively. The iodine spectra of normal cat liver and muscle glycogen and rabbit liver glycogen were similar, with absorption maxima at wavelengths of 490 to $510 \mathrm{~nm}$ (Fig. $5 \mathrm{~b}$ ). In contrast, the iodine spectra of glucans extracted from affected cat liver and muscle had absorption maxima at 560 and $585 \mathrm{~nm}$, respectively (Fig. $5 a$ ). Corn amylopectin had an absorption maximum at $540 \mathrm{~nm}$, and potato starch absorbed maximally at $610 \mathrm{~nm}$. Because the wavelength of maximum absorption in the iodine spectrum is approximately proportional to the average chain length of the glucan (23), these spectral data indicate that the affected cat glucans had longer average chain lengths than normal cat glycogen, a finding consistent with a paucity of branch points as a result of branching enzyme deficiency.

Genetic analysis. A pedigree of the purebred domestic cat family described in this report is shown in Figure 1. Cats were defined as affected when branching enzyme deficiency was demonstrated by in vitro assay and/or by tissue accumulation of abnormal glycogen. The four affected cats, two males and two females, were born to clinically normal parents in four separate but related litters. The male parents, cats no. 41 and 61 , each sired affected offspring in matings to two different but related females. Cats no. 26 and 27 were ancestors common to all of the parents of affected cats but were not available for study. Littermates of affected cats were normal on clinical examination or reported free of disease at $1 \mathrm{y}$ of age or older. The proportion of affected offspring in the affected litters was four of 14 (two of eight males and two of six females). These findings are consistent with simple autosomal recessive inheritance of glycogen storage disease type IV in this family. A G-banded karyotype (25) prepared from cultured lymphocytes of the propositus (cat no. $60)$ revealed no abnormality. 
Table 1. Enzyme activities

\begin{tabular}{|c|c|c|c|c|c|}
\hline \multirow[b]{2}{*}{ Cat identification } & \multicolumn{3}{|c|}{ Branching enzyme* } & \multicolumn{2}{|c|}{ Acid $\alpha$-glucosidase $\dagger$} \\
\hline & Muscle & Liver & Leukocytes & Muscle & Liver \\
\hline \multicolumn{6}{|l|}{ Affected: } \\
\hline no. 53 & 2.8 & 3.8 & & 23 & 44 \\
\hline no. 60 & 2.2 & 2.5 & & 27 & 41 \\
\hline no. 76 & 1.0 & 0.8 & & 12 & 39 \\
\hline \multicolumn{6}{|l|}{ Parents $\ddagger$} \\
\hline no. 33 & 5.7 & & 16 & 19 & \\
\hline no. 40 & 5.8 & & 27 & 19 & \\
\hline no. 41 & 7.0 & & 13 & 22 & \\
\hline no. $61 \S$ & 23 & & 14 & 16 & \\
\hline \multicolumn{6}{|l|}{ Littermate } \\
\hline no. 77 & 44 & & 30 & 20 & \\
\hline $\begin{array}{l}\text { Unrelated adult controls (mean } \pm \mathrm{SD} \text {, } \\
\qquad n=3 \text { ) }\end{array}$ & $33 \pm 2.3$ & $39 \pm 7.5$ & $36 \pm 4.7$ & $21 \pm 1.2$ & $55 \pm 13$ \\
\hline $\begin{array}{l}\text { Unrelated neonate controls (mean } \pm \\
\qquad \mathrm{SD}, n=3 \text { ) }\end{array}$ & $8.4 \pm 0.7$ & $17 \pm 7.2$ & & $20 \pm 6.2$ & $49 \pm 12$ \\
\hline
\end{tabular}

* Expressed in $\mu \mathrm{kat} / \mathrm{g}$ protein.

$\dagger$ Expressed in nkat/g protein.

$\ddagger$ Group means of branching enzyme activity significantly different from controls $(p<0.005)$; no significant difference between group means of acid $\alpha$-glucosidase activity.

$\S$ Cat no. 61 was also a littermate of an affected cat.

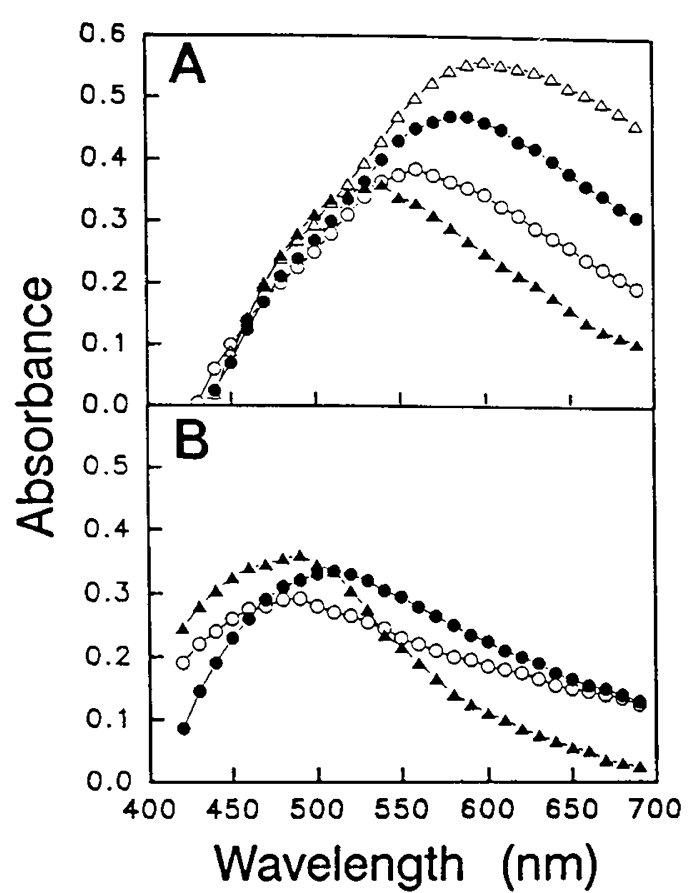

Fig. 5. Iodine spectra of reference glucans and glucans isolated from tissues of normal and glycogen storage disease type IV-affected cats. Cat glucans were isolated by hot $\mathrm{KOH}$ digestion of tissues and repeated ethanol precipitation of the resulting supernatant. Absorbance of glucans in aqueous $\mathrm{I}_{2} / \mathrm{KI}$ was determined spectrophotometrically at wavelengths between 400 and $700 \mathrm{~nm}$. Panel $A$ depicts the iodine spectra of potato starch (open triangles), corn amylopectin (filled triangles), and the glucans isolated from affected cat liver (open circles) and skeletal muscle (filled circles). Panel B depicts the iodine spectra of rabbit liver glycogen (filled triangles) and the glucans isolated from normal control cat liver (open circles) and skeletal muscle (filled circles). The abscissa is the same for both panels $A$ and $B$.

\section{DISCUSSION}

Glycogen branching enzyme deficiency causing progressive, multisystemic accumulation of a relatively unbranched glucan was found in a family of purebred domestic cats. Clinical signs of neuromuscular and cardiac disease without hepatic failure occurred in the late juvenile period and caused death in early adulthood. Branching enzyme activity was less than 0.1 of normal in liver and muscle at birth and in adulthood. Half-normal branching enzyme activity in tissues of the clinically normal parents of affected cats demonstrated a dosage effect of the mutant allele, confirming simple autosomal recessive inheritance as the mode of disease transmission. The feline disorder thus appears to be homologous to glycogen storage disease type IV in humans and is the first reported animal model of this disease.

Tissues of affected cats were examined at different ages. At birth, cytoplasmic inclusions of abnormal glycogen were present in most cardiac myocytes and a few cells of other organs. By 5 mo of age, the accumulation of abnormal glycogen was more advanced, but no degenerative changes of tissues or clinical signs of disease were seen at that time. Hyperthermia, progressive skeletal muscle atrophy, serum elevations of tissue-specific enzymes, and cardiac disease evident in the second 6 mo of life suggested degeneration of tissues that was confirmed histologically at 9 and 13.5 mo of age. Thus, although branching enzyme deficiency and accumulation of abnormal glycogen were present from birth or before in the affected cats, tissue degeneration and clinical disease were of later onset. Though possible, it cannot be assumed without further data that the affected neonate died as a result of branching enzyme deficiency because high neonatal mortality for all reasons, usually unknown, is common in inbred domestic cats (26).

The pathophysiologic basis of tissue damage in glycogen storage disease type IV of humans is not known. In the affected cats, degeneration in response to branching enzyme deficiency appeared to be an organ-specific phenomenon, with striated muscle, both skeletal and cardiac, and nervous tissue being most susceptible and other organs being relatively resistent to damage despite accumulation of the abnormal product. Evidence of both primary myopathic effects and denervation from motor neuron disease was present, but their relative contributions to the observed skeletal muscle degeneration could not be determined.

Elevated serum alanine aminotransferase activity suggested liver damage in the two cats with advanced disease, but hepatomegaly and cirrhosis, hallmarks of glycogen storage disease type IV in humans (27), were absent. This may be a reflection of differences in hepatic glycogen metabolism between cats and humans. Domestic cats have undetectable glucokinase activity and make very little liver glycogen from glucose delivered in 
plasma (28). Cats have high hepatic gluconeogenic activity whether fed or fasted, storing less hepatic glycogen than other animals, and mobilizing little hepatic glycogen when fasted (29). Therefore, the feline liver may be spared some of the deleterious effects of branching enzyme deficiency seen in human patients. It is also possible that we have not yet recognized the full range of disease presentation in cats with branching enzyme deficiency. As has been noted in some human patients $(30,31)$, diet may influence the expression of the feline disease.

Histochemical staining reactions suggested that the inclusion material in affected cat tissues was a glucan similar to normal glycogen but with a relatively unbranched structure. This conclusion was supported by the resistance of the abnormal glucan to digestion by amyloglucosidase alone, an exoglucosidase specific for $\alpha-1,4-\mathrm{D}-$ and $\alpha-1,6-\mathrm{D}$-glucosidic linkages, and its complete hydrolysis to glucose by a mixture of amyloglucosidase and $\alpha$ amylase, an endo- $\alpha-1,4$-D-glucosidase. In glycogen, the effective substrate for amyloglucosidase is the end-group concentration, which decreases exponentially as the degree of branching decreases.

Spectral analysis of the abnormal glycogen-iodine complex suggested a degree of branching intermediate to amylopectin and $\alpha$-amylose, but with less branching or longer outer chains in the glucan isolated from affected cat muscle than in that isolated from affected cat liver (23). Variation in the iodine spectra of the glucans isolated from different tissues of the same patient has also been noted in reports of the human disease $(2,7,10)$. Synthesis of glycogen is the coordinated activity of branching enzyme and glycogen synthase (EC 2.4.1.11), an enzyme activity that is regulated over a wide range. Reported data suggest that within a certain range the activity of these two enzymes, relative to each other, may determine the degree of branching of the product (32). Thus, although branching enzyme activity may always be in relative excess in normal tissues, in human or feline patients with branching enzyme deficiency, the tissue-specific degree of glycogen branching may depend on the state of glycogen synthase activation in that tissue. Alternatively, branching enzyme expression may be tissue specific, whether a product of a normal gene or one altered by mutation.

Residual glycogen branching activity is the likely origin of branch points in the glycogen of branching enzyme-deficient people and cats. Such activity has been demonstrated in cultured fibroblasts of patients with glycogen storage disease type IV, supporting a near-normal degree of glycogen branching in homogenates of those cells in vitro (33). Recent studies in Saccharomyces cerevisiae suggest that branching enzyme mutations that reduce but do not eliminate activity result in production of glycogen with decreased branching and in slightly reduced amount, whereas null mutations result in severely reduced glucan production (34). Because glycogen metabolism is fundamental to glucose homeostasis and fulfillment of energy requirements in the developing fetus (35), null mutations of branching enzyme in mammals may be incompatible with fetal development or perinatal survival, thereby restricting the surviving population of neonates with branching enzyme deficiency to those with some minimal residual branching enzyme activity.

A consistent electron microscopic finding in tissues of humans affected with glycogen storage disease type IV is the accumulation of normal-appearing glycogen particles on the periphery of abnormal fibrillar inclusions $(5,8,9,10,12,13,27,30,36)$. These were not seen in skeletal myocytes or neurons in the 9-mo-old affected cat examined by electron microscopy (cat no. 60, Fig. 4 ), a difference from the human disease that we cannot explain at this time. It appears consistent, however, with the longer wavelengths of peak absorption in the iodine spectra of abnormal glycogen from affected cats than in those reported for human patients (560-585 versus 520-540 nm, respectively) $(2,3,6,7$, $10,16,31,36)$, suggesting that the affected cat glucan is less branched than that of reported human patients.

To date, feline glycogen storage disease type IV is confined to a single family and will therefore allow analysis of the consequences of a single mutation affecting branching enzyme activity in several tissues. Though unproven at this time, it is likely that much of the variation among human patients in the expression of this disease is due to the effects of different mutations in the branching enzyme locus or to mutations in undefined genetic loci controlling tissue-specific expression of glycogen branching activity. This feline model should facilitate studies to approach many of the pathophysiologic problems posed by glycogen storage disease type IV in human patients. A breeding colony derived from a relative of the described cats has been established.

Acknowledgments. The authors thank James E. Hayden for electron microscopy and William R. Schnarr for technical assistance in the application of special stains.

\section{REFERENCES}

1. Andersen DH 1956 Familial cirrhosis of the liver with storage of abnormal glycogen. Lab Invest 5:11-20

2. Sidbury Jr JB, Mason J, Burns Jr WB, Ruebner BH 1962 Type IV glycogenosis. Report of a case proven by characterization of glycogen and studied at necropsy. Bull Johns Hopkins Hosp 111:157-181

3. Brown BI, Brown DH 1966 Lack of an $\alpha$-1,4-glucan: $\alpha$-1,4-glucan 6-glycosyl transferase in a case of type IV glycogenosis. Proc Nat Acad Sci USA 56:725729

4. Reed Jr GB, Dixon JFP, Neustein HB, Donnell GN, Landing BH 1968 Type IV glycogenosis patient with absence of a branching enzyme $\alpha$-1,4-glucan: $\alpha$-1,4-glucan 6-glycosyl transferase. Lab Invest 19:546-557

5. Ishihara $T$, Uchino $F$, Adachi $H$, Takahashi $M$, Watanabe $S$, Tsunetoshi $S$, Fugi T, Ikee Y 1975 Type IV glycogenosis: a study of two cases. Acta Pathol Jpn 25:613-633

6. Illingworth B, Cori GT 1952 Structure of glycogens and amylopectins. III. Normal and abnormal human glycogen. J Biol Chem 199:653-660

7. Holleman LWJ, van der Harr JA, de Vann GAM 1966 Type IV glycogenosis. Lab Invest 15:357-367

8. McMaster KR, Powers JM, Hennigar Jr GR, Wohltmann HJ, Farr Jr GH 1979 Nervous system involvement in type IV glycogenosis. Arch Pathol Lab Med 103:105-111

9. Schochet Jr SS, McCormick WF, Zellweger H 1970 Type IV glycogenosis (amylopectinosis) light and electron microscopic observations. Arch Pathol 90:354-363

10. Servidei S, Riepe RE, Langston C, Tani LY, Bricker JT, Crisp-Lindgren N, Travers H, Armstrong D, DiMauro S 1987 Severe cardiomyopathy in branching enzyme deficiency. J Pediatr 111:51-56

11. Zellweger H, Mueller S, Ionasescu V, Schochet SS, McCormick WF 1972 Glycogenosis IV: a new cause of infantile hypotonia. J Pediatr 80:842-844

12. Greene HL, Brown BI, McClenathan DT, Agostini Jr RM, Taylor SR 1988 A new variant of type IV glycogenosis: deficiency of branching enzyme activity without apparent progressive liver disease. Hepatol 8:302-306

13. Guerra AS, van Diggelen OP, Carneiro F, Tsou RM, Simoes S, Teixeira Santos N 1986 A juvenile variant of glycogenosis IV (Andersen disease). Pediatrics 145:179-181

14. Selby R, Starzl TE, Yunis E, Brown BI, Kendall RS, Tzakis A 1991 Liver transplantation for type IV glycogen storage disease. N Engl J Med 324:39 42

15. Legum CP, Nitowsky HM 1969 Studies on leukocyte brancher enzyme activity in a family with type IV glycogenosis. J Pediatr 74:84-89

16. Howell RR, Kaback MM, Brown BI 1971 Type IV glycogen storage disease branching enzyme deficiency in skin fibroblasts and possible heterozygote detection. J Pediatr 78:638-642

17. Brown BI, Brown DH 1989 Branching enzyme activity of cultured amniocytes and chorionic villi: prenatal testing for type IV glycogen storage disease. Am J Hum Genet 44:378-381

18. Haskins ME, Jezyk PF, Patterson DF 1979 Mucopolysaccharide storage disease in three families of cats with arylsulfatase B deficiency: leukocyte studies and carrier identification. Pediatr Res 13:1203-1210

19. Wolfe JH, Haskins ME, Zmijewski CM 1984 Mixed lymphocyte reactivity in cats. Transplantation 37:509-513

20. Lowry OH, Rosebrough NJ, Farr AL, Randall RJ 1951 Protein measurement with the folin phenol reagent. J Biol Chem 193:265-275

21. Walvoort HC, Slee RG, Koster JF 1982 Canine glycogen storage disease type II: a biochemical study of an acid $\alpha$-glucosidase-deficient Lapland dog. Biochim Biophys Acta 715:63-69

22. Somogyi M 1934 The solubility and preparation of phosphorus- and nitrogenfree glycogen. J Biol Chem 104:245-253

23. Archibald AR, Fleming ID, Liddle AM, Manners DJ, Mercer GA, Wright A $1961 \alpha-1,4$-glucans. Part XI. The absorption spectra of glycogen- and amylopectin-iodine complexes. J Chem Soc: 1183-1190

24. Keppler D, Decker K 1974 Glycogen determination with amyloglucosidase. In: Bergmeyer HU (ed) Methods of Enzymatic Analysis. Academic Press, New York, pp 1127-1131

25. O'Brien SJ, Nash WG 1982 Comparative genetic mapping in mammals: chromosome map of the domestic cat. Science 216:257-265 
26. Peltz RS 1975 Mortality rates in kittens and young cats. Carniv Genet Newsl 2:308-311

27. Hers H, Van Hoof F, de Barsy T 1989 Glycogen storage diseases. In: Scriver CR, Beaudet AL, Sly WS, Valle D (eds) The Metabolic Basis of Inherited Disease. McGraw-Hill, New York, pp 425-452

28. Ballard FJ 1965 Glucose utilization in mammalian liver. Comp Biochem Physiol 14:437-443

29. Kettlehut IC, Foss MC, Migliorini RH 1980 Glucose homeostasis in a carnivorous animal (cat) and in rats fed a high-protein diet. Am J Physiol 239:R437R444

30. Greene HL, Ghishan FK, Brown B, McClenathan DT, Freese D 1988 Hypoglycemia in type IV glycogenosis: hepatic improvement in two patients with nutritional management. J Pediatr 112:55-58

31. Levin B, Burgess EA, Mortimer PE 1968 Glycogen storage disease type IV amylopectinosis. Arch Dis Child 43:548-555
32. Smith EE 1968 Enzymic control of glycogen structure. In: Whelan WJ (ed) Control of Glycogen Metabolism. Academic Press, New York, pp 203-213

33. Brown DH, Brown BI 1983 Studies of the residual glycogen branching enzyme activity present in human skin fibroblasts from patients with type IV glycogen storage disease. Biochem Biophys Res Comm 111:636-643

34. Rowen DW, Meinke M, LaPorte DC 1992 GLC3 and GHA I of Saccharomyces cerevisiae are allelic and encode the glycogen branching enzyme. Mol Cell Biol 12:22-29

35. Philipps AF 1992 Carbohydrate metabolism of the fetus: general metabolism and glucose. In: Polin RA, Fox WW (eds) Fetal and Neonatal Physiology. WB Saunders, Philadelphia, pp 373-384

36. Bannayan GA, Dean WJ, Howell RR 1976 Type IV glycogen-storage disease. Am J Clin Pathol 66:702-709 